\title{
Restauração do diafragma de cão com centro tendinoso de ovino conservado em glicerina a $98 \%$
}

\section{Ovine tendinous diaphragm preserved in $98 \%$ glycerin for reconstruction of canine diaphragmatic muscle}

\author{
Alexandre Mazzanti, ${ }^{*}$ Ney Luis Pippi, ${ }^{\star *}$ Alceu Gaspar Raiser, ${ }^{\star \star \star *}$ Dominguita Lühers Graça, ${ }^{* \star \star *}$ Renato Xavier Faria, ${ }^{*}$ \\ Luciana Oliveira de Oliveira, ${ }^{\star \star \star \star *}$ Luciana Dambrósio Guimarães*
}

\begin{abstract}
Resumo
Foram utilizados 12 cães, adultos, sem raça definida, pesando entre 13 e $21 \mathrm{~kg}$ com o objetivo de estudar o processo cicatricial de um segmento de centro tendinoso de ovino conservado em glicerina a $98 \%$ no reparo de defeito no músculo diafragma de cão. Foi removido um segmento na porção muscular do diafragma, de dimensões $6,0 \times 4,5 \mathrm{~cm}$, para posterior implantação de centro tendinoso heterólogo, mediante toracotomia no $10^{\circ}$ espaço intercostal direito. Seis cães foram obșervados por um período de 30 dias de pós-operatório e, o restante, por 60 dias, quando foram reoperados para observação macroscópica e coleta de amostras para avaliação histológica. Foi verificada, aos 30 dias, substituição parcial e, aos 60 , substituição total do enxerto por tecido fibrovascular, permitindo o restabelecimento completo do diafragma por meio de firme inserção. Macroscopicamente foi notado, na cavidade torácica, maior índice de aderência com a pleura parietal e, na cavidade abdominal, com o fígado, porém, sem comprometimento clínico. O segmento de centro tendinoso de ovino conservado em solução de glicerina a $98 \%$, em temperatura ambiente, pode ser utilizado para reparo de defeitos diafragmáticos, uma vez que suporta o gradiente de pressão no diafragma e é substituído por tecido cicatricial, sem apresentar sinais clínicos e histológicos de rejeição.
\end{abstract}

Palavras-chave: implante; centro tendinoso; cão; hernioplastia diafragmática.

\begin{abstract}
The aim of this study was to evaluate the healing process of an implant of ovine tendinous diaphragm preserved in $98 \%$ glycerin for the repair of iatrogenic defect of diaphragmatic muscle in dogs. In this experiment, twelve adult mongrel dogs, six males, weighting 13 to $21 \mathrm{~kg}$ were used. A diaphragmatic wound of $6.0 \times 4.5 \mathrm{~cm}$ on the muscular portion of the diaphragm was created through thoracotomy at the $10^{\text {th }}$ intercostal space. An implant of heterologous diaphragmatic segment was used to repair the iatrogenic defect. Six dogs were observed for a post-operative period of 30 days and, the remaining dogs, for 60 days. After these periods, the dogs were operated for macroscopic evaluation and collection of samples for histological exams. In the 30 daysgroup, partial replacement of the graft by fibrovascular tissue was verified. In the animals of the 60 days-group, total replacement was achieved, which allowed strong and total reestablishment of the diaphragmatic muscle. Macroscopically, higher numbers of adherences with the parietal pleura were observed in the thoracic cavity, and, with the liver, in the abdominal cavity. Clinical complications related to the adherences were not observed. The segment of ovine tendinous diaphragm preserved in $98 \%$ glycerin, at room temperature, can be used for the repair of diaphragmatic muscle defects in dogs, because it supports the gradient pressure of the diaphragm and is replaced by connective tissue, without clinical and histological signs of rejection.
\end{abstract}

Keywords: implant; tendinous center; dog; diaphragmatic hernioplasty.

\section{Introdução}

A incidência de hérnia diafragmática em medicina veterinária é relativamente alta, tendo o traumatismo como seu principal causador de lesões (Levine, 1987; Hosgood, 1996; Burton e White, 1997). Os defeitos diafragmáticos ocasionam altera- ções circulatórias e respiratórias (Boudrieau, 1993), que podem levar a óbito, se procedimentos clínico-cirúrgicos não forem realizados (Burton e White, 1997). Pelas alterações anatômicas provocadas no tecido diafragmático, o tratamento clínico pode ser empregado como terapia de suporte, sendo indispensável a correção cirúrgica (Daleck et al., 1988).

\footnotetext{
* Pós-graduação. Universidade Federal de Santa Maria (UFSM). Hospital Veterinário. Faixa de Camobi, Km 9,5 CEP 97105-900 mazzal@lince.hcv.ufsm.br - Autor para correspondência.

**Departamento de Clínica de Pequenos Animais, UFSM.

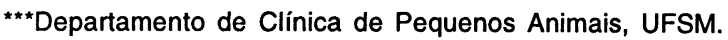

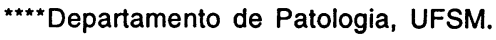

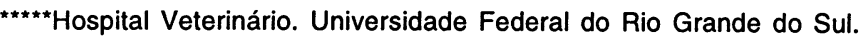


Em lesões de pequenas extensões sem perda tecidual, a aproximação cirúrgica das bordas da ferida permite a cicatrização adequada do diafragma (Barreiros et al., 1996), o que não é recomendado para grandes defeitos (Speirs e Reynolds, 1976).

Latteri et al. (1966) utilizaram para reparação de hérnia diafragmática em cão, dura-máter homóloga esterilizada em betapropiolactona e conservada em liqüido de Hamks e notaram que o enxerto restaurou o defeito, servindo como suporte temporário para o desenvolvimento de proliferação de tecido conjuntivo, sem demonstrar intensa reação do tipo corpo estranho. Já Rodgers et al. (1981) estudaram dura-máter humana esterilizada em solução de betapropiolactona a $1 \% \mathrm{e}$ conservada em solução salina-plasma e verificaram que a lesão foi reparada mediante incorporação do enxerto com formação de fibras colágenas. Gallo et al. (1982) testaram pericárdio de bovino e suíno conservado em solução de glutaraldeído. Os resultados demonstraram boa vedação do defeito e presença de uma camada de tecido conjuntivo na área de enxertia. Daleck et al. (1988) avaliaram peritônio de bovino conservado em glicerina a $98 \%$, sendo notada oclusão do defeito com formação de aderências de órgãos abdominais e torácicos na área de enxertia. Histologicamente, foi observado no $60^{\circ}$ dia de pós-operatório, que o enxerto de peritônio estava sendo substituído por tecido conjuntivo, na presença de células inflamatórias.

A glicerina vem sendo utilizada para a preservação de materiais biológicos (Daleck et al., 1988; Ranzani et al., 1990), por ser atenuador antigênico, preservar a elasticidade do material biológico e possuir o efeito bactericida (Pigossi et al., 1971; Leite et al., 1979).

Neste experimento objetivou-se avaliar o comportamento de um segmento de centro tendinoso do diafragma de ovinos conservado em solução de glicerina a $98 \%$ na restauração de um defeito no músculo diafragma de cão, por meio de análise macro e microscópica da área de enxertia.

\section{Material e métodos}

Foram utilizados 12 cães adultos, sem raça definida, com peso variando entre 13 a $21 \mathrm{~kg}$, oriundos do Biotério Central da Universidade Federal de Santa Maria, que permaneceram sob observação clínica por período de sete dias, e após serem vermifugados, foram mantidos em canis individuais com alimentação e água à vontade. Os animais foram separados em dois grupos de igual número para avaliação até 30 dias (grupo I) e 60 dias (grupo II) de pós-operatório. Após jejum prévio de 12 horas, os animais foram tranqüilizados com maleato de acepromazina ${ }^{1}(0,1 \mathrm{mg} / \mathrm{kg}$, IV) e a região torácica lateral direita tricotomizada. Realizou-se a indução anestésica com thiopental sódico² 2,5\% (12,0 mg/kg de peso corporal, IV) e após intubação oro-traqueal, foram mantidos em plano cirúrgico sob anestesia inalatória com halotano ${ }^{3}$ e ventilados por pressão positiva com oxigênio. Com a contenção dos animais em decúbito lateral esquerdo, realizou-se anti-sepsia do campo operatório com álcool-iodo-álcool.

\footnotetext{
1 Acepran $1 \%$. Univet S.A. São Paulo, SP.

2 Thionembutal. Abbot Laboratório do Brasil. São Paulo, SP.

3 Halotane. Cristália do Brasil. São Paulo, SP.
}

Cada segmento de centro tendinoso foi obtido de ovino abatido em matadouro, e não apresentava alterações macroscópicas. Foi preparado após a remoção de todo o músculo diafragma, preservando somente sua porção tendinosa. Em seguida, foi banhado com solução fisiológica $\mathrm{NaCl} 0,9 \%$ e colocado em frasco contendo glicerina a $98 \%$, em temperatura ambiente, permanecendo imerso por período não inferior a 30 dias. Foi removido do frasco com solução de glicerina a $98 \%, 15$ minutos antes do procedimento cirúrgico, enxaguado abundantemente com solução salina e imerso em cuba estéril contendo solução fisiológica à temperatura ambiente, para reidratação. O centro tendinoso foi preparado confeccionando-se um segmento de dimensões suficientes para ocluir o defeito diafragmático provocado.

O músculo diafragma foi acessado mediante toracotomia no $10^{\circ}$ espaço intercostal direito, identificado e, com auxílio de um lâmina radiográfica estéril de dimensões $6,0 \times 4,5 \mathrm{~cm}$, demarcado no lado direito com quatro pontos de reparos com fio poliamida ${ }^{4} 0,25$ em cada ângulo. Em seguida, o tecido entre pontos foi removido, com bisturi, resultando num defeito. O segmento de centro tendinoso heterólogo foi fixado às bordas da ferida diafragmática pelos quatro pontos anteriormente empregados como reparos e a sutura foi completada, com pontos do tipo Wolff, com sobreposição de bordas, e de modo que os nós permanecessem sobre a face torácica do enxerto.

A toracorrafia foi realizada com pontos simples contínuos e a pele foi suturada com pontos simples separados utilizando poliamida 0,30 . O restabelecimento da pressão negativa intratorácica foi feito por inserção de agulha $30 \times 28$ no terço médio do $7^{\circ}$ espaço intercostal, adaptada a seringa de $60 \mathrm{ml}$, com auxílio de torneira de três vias.

Foram utilizados ampicilina sódica ${ }^{5}(20,0 \mathrm{mg} / \mathrm{kg}$, IV), trinta minutos antes do início da cirurgia e flunixin meglumine ${ }^{6}(1,0$ $\mathrm{mg} / \mathrm{kg}$, IV), logo após o término da cirurgia e por via intramuscular, durante dois dias. A ferida cutânea foi submetida a limpeza com solução fisiológica de $\mathrm{NaCl}$ a $0,9 \%$ durante dez dias e os pontos de pele retirados com oito dias de pós-operatório.

Os animais do grupo I foram avaliados clinicamente por 30 dias e os do grupo II por 60, quando foram reoperados para avaliação macroscópica e coleta de fragmentos da área de enxertia, para estudo em microscopia óptica. Os cortes histológicos foram corados pela técnica de hematoxilinaeosina (HE) e tricrômico de Masson (TM).

\section{Resultados e discussão}

Nenhum dos cães apresentou complicações pós-operatória ou evidência clínica de solução de continuidade no diafragma.

O uso de pontos de reparo foi de fundamental importância na aplicação da técnica cirúrgica, por permitir uma abordagem ao músculo diafragma, evitando manipulação excessiva no momento da sutura, semelhante aos resultados encontrado por Daleck et al. (1988), utilizando peritônio de bovinos e

\footnotetext{
${ }^{4}$ Fio poliamida - Araty Superflex. São Paulo, SP.

${ }^{5}$ Ampicilina sódica Ariston. Ariston Indústria Química. São Paulo, SP.

${ }^{6}$ Banamine. Schering-Plough. Rio de Janeiro, RJ.
} 
Eurides et al. (1994), peritônio-muscular autólogo, na reparação de diafragma de cão.

Várias são as alternativas de acesso ao músculo diafragma, como via tóraco-abdominal praticada por Punch e Slatter (1985); $8^{\circ}$ espaço intercostal empregado por Gallo et al. (1982) e Edington et al. (1989); laparotomia mediana por Rodger et al (1981) e Sullivan e Reid (1990), e abdominal por Ranzani et al. (1990). O acesso ao diafragma por toracotomia foi o mesmo adotado por Levine (1987) e Daleck et al. (1988), sendo eficiente e permitindo a fixação e sutura do enxerto ao músculo diafragma, sem interferência no campo cirúrgico durante a expansão pulmonar.

$\mathrm{Na}$ avaliação microscópica, verificou-se, ao redor do fio de sutura, a presença de reação fibrosa, com células inflamatórias. George e Mohammed (1993), obtiveram maior reação tecidual com o náilon e menor com o dacron. Já Matsumoto et al. (1996), observaram proliferação de tecido conjuntivo e infiltração de células inflamatórias, aos 30 dias, principalmente na área da sutura do implante com o diafragma. No atual experimento, o fio de sutura utilizado foi o poliamida que se mostrou resistente e de fácil manuseio além de suportar o gradiente de pressão sobre o diafragma, confirmado pela ausência de hérnia diafragmática durante o exame macroscópico da área de enxertia.

A fixação do implante com pontos de Wolff com sobreposição de bordas facilitou a aproximação dos tecidos sem ocasionar tensão excessiva na sutura, prevenindo a deiscência, fato também notado por Edington et al. (1989) e Barreiros et al. (1996).

Foram observadas aderências entre a área implantada e os órgãos abdominais e torácicos adjacentes nos animais de 30 e 60 dias de pós-operatório. Entre as estruturas abdominais, o fígado (50\%) teve maior índice de aderência, à semeIhança do observado por Ranzani et al. (1990), Matsumoto et al. (1996) e Oliveira e Pippi (1998). Isso ocorreu devido ao posicionamento do defeito diafragmático no terço médio da porção muscular direita e sua relação próxima com o fígado. Entre as estruturas torácicas, a pleura parietal foi encontrada aderida na área de enxertia em todos os animais do grupos I e II, ao contrário de Ranzani et al. (1990), com pericárdio de eqüino, que verificaram maior aderência com o pulmão. $A$ formação de aderências entre o enxerto e os órgãos abdominais e torácicos ocorreu devido à presença do enxerto que é isquêmico e induziu uma reação inflamatória para revascularização, o que resultou em formação de aderência fibrosa. Este resultado, no entanto, não ocasionou, durante o período de observação, comprometimento clínico das estruturas envolvidas, como relatado por Eurides et al. (1994) e Oliveira e Pippi (1998). Essa aderência não deve preocupar, pois favorece a substituição do enxerto e não traz efeito colateral ao paciente.

$\mathrm{Na}$ avaliação microscópica da área de enxertia no 30 일 de pós-operatório (grupo I), verificou-se que as fibras colágenas do centro tendinoso de ovino foram quase totalmente substituídas por tecido conjuntivo fibroso, rico em fibras colágenas com completa união das bordas do defeito diafragmático. Os mesmos resultados foram observados no $60^{\circ}$ dia de pósoperatório (Grupo II); porém, com total substituição por tecido conjuntivo (Figura 1), caracterizando o processo cicatricial, como verificado por Eurides et al. (1994), empregando segmento de peritônio-muscular e Rodgers et al. (1981) com dura-máter heteróloga. Esses resultados demostram que o enxerto comportou-se inicialmente como estrutura de sustentação temporária, permitindo proteção mecânica da ferida até o momento da ocorrência da reparação por tecido conjuntivo. $O$ infiltrado de células mononucleares na região de enxertia pode ser explicado pelas presenças do centro tendinoso heterólogo e do fio de sutura, coincidindo com os achados de Eurides et al. (1994) e Barreiros et al. (1996). Em nenhum dos animais verificou-se, durante o estudo histológico, a presença de necrose ou reações celulares da área reparada, que sugerissem sinais de rejeição, fato também verificado por Pigossi et al. (1971).

A hidratação de um segmento de centro tendinoso de ovino em solução salina estéril, 15 minutos antes da implantação, manteve a consistência do enxerto próximo do original, analogamente aos achados de Daleck et al. (1988), com peritônio de bovino conservado em glicerina a $98 \%$.

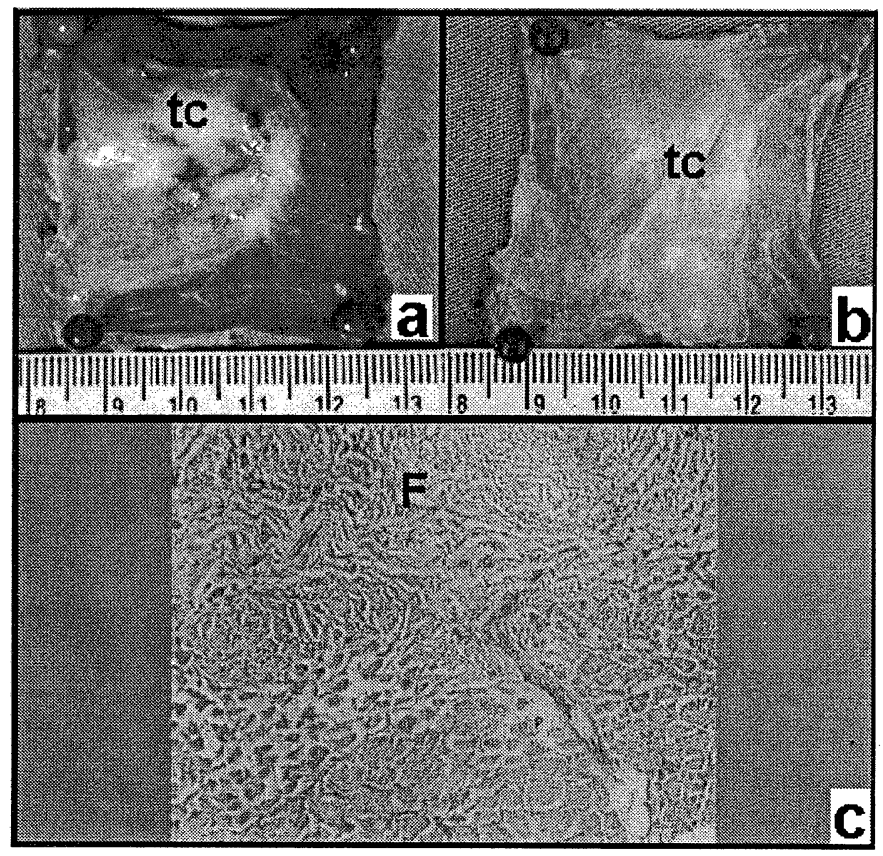

Figura 1 - Aspectos macroscópico e microscópico do músculo diafragma de cão, decorridos 60 dias da implantação de segmento tendinoso conservado em solução de glicerina a $98 \%$. Notam-se as faces abdominal (a) e torácica (b) da área de implantação, formação de tecido conjuntivo (tc) sobre o músculo diafragma cicatrizado. Em (a), verificam-se, na área de enxertia, fragmentos de parênquima hepático aderido. Microscopicamente (c), observa-se sobre a área do implante, presença de tecido fibrovascular (F), rico em fibras colágenas, substituindo o enxerto muscular. Obj. 04. TM.

Foi descrito por Daleck et al. (1988) que os materiais biológicos ao serem comparados com outros tipos de enxerto, têm como vantagem possibilitar a incorporação ao tecido receptor. Para isso, a conservação é de fundamental importância, a fim de manter a sua viabilidade como salientado por Pigossi et al. (1971). O enxerto de centro tendinoso de ovinos conservado em solução de glicerina a $98 \%$ manteve aparente resistência durante a sua manipulação à semelhança dos resultados obtidos por Daleck et al. (1988) com peritônio de bovino, e Ranzani et al. (1990), com pericárdio de eqüinos. Neste 
experimento, apesar da não realização de estudos bacteriológicos da solução e imuno-histoquímicos do enxerto, não foram detectados, durante o período de observação, sinais clínicos de infecção e rejeição, corroborando com os achados de Pigossi et al. (1971), quando utilizaram dura-máter homóloga como substituto dural em cão e por Leite et al. (1979).

\section{Referências}

BARREIROS, L.J., RODASKI, S., SUSKO, I. et al. Uso experimental do músculo grande dorsal na reparação dos grandes defeitos diafragmáticos no cão. Rev. Set. Ciênc. Agr., Curitiba, v. 15, n. 1, p. 141-150, 1996.

BOUDRIEAU, R.J. Pathophysiology of traumatic diaphragmatic hernia. In: BOJRAB, J. Diseases mechanisms in small animall surgery. Philadelphia: Lea \& Febiger, 1993, p. 103-108.

BRIGHT, R.M., THACKER, H.L. The formation of an omental pedicle flap and its experimental use in the repair of na diaphragmatic rent in the dog. J. Am. Anim. Hosp. Assoc., v. 18, n. 2, p. 283-289, 1982.

BURTON, C., WHITE, R. Surgical approach to a ruptured diaphragm in the cat. In Pract., v.19, n. 6, p. 298-305, 1997.

DALECK, C.R., DALECK, C.L.M., ALESSI, A.C., et al. Substituição de um retalho diafragmático de cão por peritônio de bovino conservado em glicerina: estudo experimental. Ars Vet., v. 4, n. 1, p. 53-61, 1988.

EDINGTON, H.D., EVANS, S., SINDELAR, W.F. Reconstruction of a funcional hemidiaphragm with use of omentum and latissimus dorsi flaps. Surg., v. 105, n. 3, p. 442-445, 1989.

EURIDES, D., NIGRO, A.J.T., GOLDENBERG, S., et al. Reparo de defeito provocado no diafragma de cães com segmento livre peritônio-muscular: estudo experimental. Acta Cir. Bras., v. 9, n. 3., p. 131-135, 1994.

GALLO, J.I., ARTIÑANO, E., VAL, F., et al. Glutaraldehyde-preserved heterologous pericardium for the repair of diaphragmatic defects. $J$. Thorac. Cardiovasc. Surg., v. 83, n. 6, p. 905-908, 1982.

GEORGE, R.S., MOHAMMED, M.S.D.M. Studies on diaphragmatic herniorrhaphy with different prosthetic materials. Indian Vet. J., v. 70 , p. 255-257, 1993.

HELPHREY, M.L. Abdominal flap graft for repair of chronic diaphragmatic hernia in the dog. J. Am. Vet. Med. Assoc., v. 181, n. 8, p. 791-793, 1982.

HOSGOOD, G. Diagnosis and management of diseases of the diaphragm. Walthan Focus, v. 6, n. 8, p. 2-9, 1996.

\section{Conclusão}

Os resultados desta pesquisa permitem concluir, no período de tempo avaliado, que segmento de centro tendinoso de ovino conservado em glicerina a $98 \%$, em temperatura ambiente, pode ser utilizado para reparação de defeito diafragmático de cão, pois suporta o gradiente de pressão no diafragma e é substituído por tecido cicatricial.

LATTERI, S., BIONDI, M., ROMEO, G., et al. Ricerche sperimentali sulla riparazioni di diffetti diafragmmatic com dura madre. Gac. Ital. Chir., v. 22, n. 5, p. 171-196, 1966.

LEITE, J.B.F., MARQUES, A.F., GOMES, O.M., et al. A glicerina e a preservação de tecidos. Rev. Paul. Med., v. 93, n. 3-4, p. 81-84, 1979.

LEVINE, S.H. Diaphragmatic hernia. Vet. Clin. North Am. Small Anim. Pract., Philadelphia, v. 17, n. 2. p. 411-430, 1987.

LIN, A.C. Closure of diaphragmatic defect by gut segment transplantation in dogs. Mem. Coll. Agri., v. 13, n. 1, p. 190-195, 1972.

MATSUMOTO, H., OGUCHI, Y., MIYAKE, Y. et al. The use of epoxy patch grafts for repair of experimentally-created diaphragmatic defects in dogs. J. Vet. Med. Sci., v. 58, n. 7, p. 685-687, 1996.

OLIVEIRA, L.O., PIPPI, N.L. Retalho pediculado do músculo grande dorsal para reparo de defeito diafragmático em cães. Santa Maria RS. 1998.15 p. Seminário-Programa de Pós-graduação em Medicina Veterinária. Universidade Federal de Santa Maria, 1998.

PIGOSSI, N., RAIA, A., LEX, A., et al. Estudo experimental sobre o emprego, como implante, da dura-máter homógena conservada em glicerina à temperatura ambiente. Rev. Assoc. Med. Bras., v. 17, n. 8, p. 263-278, 1971.

PUNCH, P.I., SLATTER, D.H. Diaphragmatic hemias. In: SLATTER, D.H. Textbook of small animal surgery. Philadelphia: Saunders, 1985. Cap. 59, p. 869-885.

RANZANI, J.J.T., GANDOLFI, W., FRANCO, M., et al. Implante de pericárdio de eqüino em glicerina em solução de continuidade do diafragma de cão. Braz. J. Vet. Res. Anim. Scie., v. 27, n. 1, p. 65-73, 1990.

RODGERS, B.M., MAHER, J.W., TALBERT, J.L. The use of preserved human dura for closure of abdominal wall and diaphragmatic defects. Ann. Surg., v. 195, n. 3, p. 606-611, 1981.

SPEIRS, V.C., REYNOLDS, W.T. Sucessful repair of a diaphragmatic hernia in a foal. Equine Vet. J., v. 8, n. 1, p. 170-172, 1976.

SULLIVAN, M., REID, J. Management of 60 cases of diaphragmatic rupture. J. Small Anim. Pract., v. 31, n. 9, p. 425-430, 1990. 